\section{Extending Ion Engine Technology to NEXT and Beyond}

M. T. Domonkos, M. J. Patterson, J. E. Foster, V. K. Rawlin, G. C. Soulas, J. S. Sovey, S. D. Kovaleski, R. F. Roman, and G. J. Williams, Jr.

\section{NASA John H. Glenn Research Center Mail Stop 301-3 21000 Brookpark Road Cleveland, OH 44135}

Extending ion engine technology beyond the current state-of-theart primary interplanetary electric propulsion system, the $2.3-\mathrm{kW}$ NASA Solar Electric Propulsion Technology and Applications Readiness (NSTAR) system, will require thrusters with improved propellant throughput and total impulse capability. Many of the design choices that culminated in the NSTAR thrusters must be revisited, and their application to next generation ion engine technology must be evaluated. The concept of derating, which was successfully employed in NSTAR, has been applied to the 40cm NASA Evolutionary Xenon Thruster (NEXT) currently under development at NASA Glenn Research Center (GRC). At 5-kW, NEXT operates with the same average beam current density as NSTAR, and at $10-\mathrm{kW}$, the peak beam current density is only ten percent greater than NSTAR. The result is that similar ion optics technology is expected to yield comparable lifetime. Thickaccelerator-grid ion optics are also being tested to realize additional lifetime benefits. A 40-A discharge cathode is being developed for NEXT based on scaling the NSTAR design.

Nevertheless, the experiences of the NSTAR ground tests and the thruster on the Deep Space One spacecraft indicate that the discharge cathode wear must be studied experimentally and theoretically to ensure that it meets the lifetime requirements. Although NEXT is in its infancy, investigations have already begun to examine possible modifications to engine design for even higher-power and higher-specific impulse engines. Ion optics using alternate materials such as titanium, graphite, or carboncarbon composite are currently being investigated due to their low sputter yields at high voltage. To avoid the difficulties

encountered using electrodes at high-currents, the use of a microwave-based ion thruster is under investigation for potential high-power ion thruster systems requiring long lifetimes.

Additionally, alternative propellants are being considered for applications requiring high-specific impulse $(>5000 \mathrm{~s})$ and extremely long-life ( $>15,000 \mathrm{hr}$ ). Testing requirements make condensable propellants attractive for high-power engines.

Although the NSTAR ion engine demonstrated the flight maturity of ion thruster technology, many challenges remain for the development of thrusters with improved propellant throughput and power handling capabilities.
ICOPS $_{2002}$

International Conference on Plasma Science
Abstract Submitted for the 29th IEEE International Conference on Plasma Science May 26-30, 2002

Banff, Alberta, Canada

Abstracts should be submitted by e-mail using this MS Word file.

Subject Topic_Plasma Thrusters

Subject Number _ $\quad 5.3$

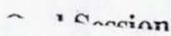

Province $\_$Zip Code _ _4135
Country _USA
Phone _216-433-2164
Fax_216-433-2657__.Domonkos@grc.nasa.gov__

Abstract must be received no later than Jan. 18, 2002

e-mail to: icops2002@ee.ualberta.ca

If submitting by mail send original and two copies to:

\title{
ICOPS2002
}

Lee Grimard

423 Department of Physics

University of Alberta

Edmonton, AB Canada T6G 2J1

This is a preprint or reprint of a paper intended for presentation at a conference. Because changes may be made before formal publication, this is made available with the understanding that it will not be cited or reproduced without the permission of the author. 


\section{Extending Ion Engine Technology to NEXT and Beyond}

Matthew T. Domonkos, Michael J. Patterson, John E. Foster, Vince K. Rawlin, George C. Soulas, James S. Sovey, Scott D. Kovaleski, Robert F. Roman, and George J. Williams, Jr.

Matthew.T.Domonkos@grc.nasa.gov http://www.grc.nasa.gov/www/ion/ 
- Ion Propulsion Roles

- Ion Engine Design

- SOA Performance and Life

- Extending Performance Beyond the SOA

- Extending Life for NASA's Evolutionary Xenon Thruster (NEXT)

- Extending Life Significantly Beyond NEXT

- Summary 


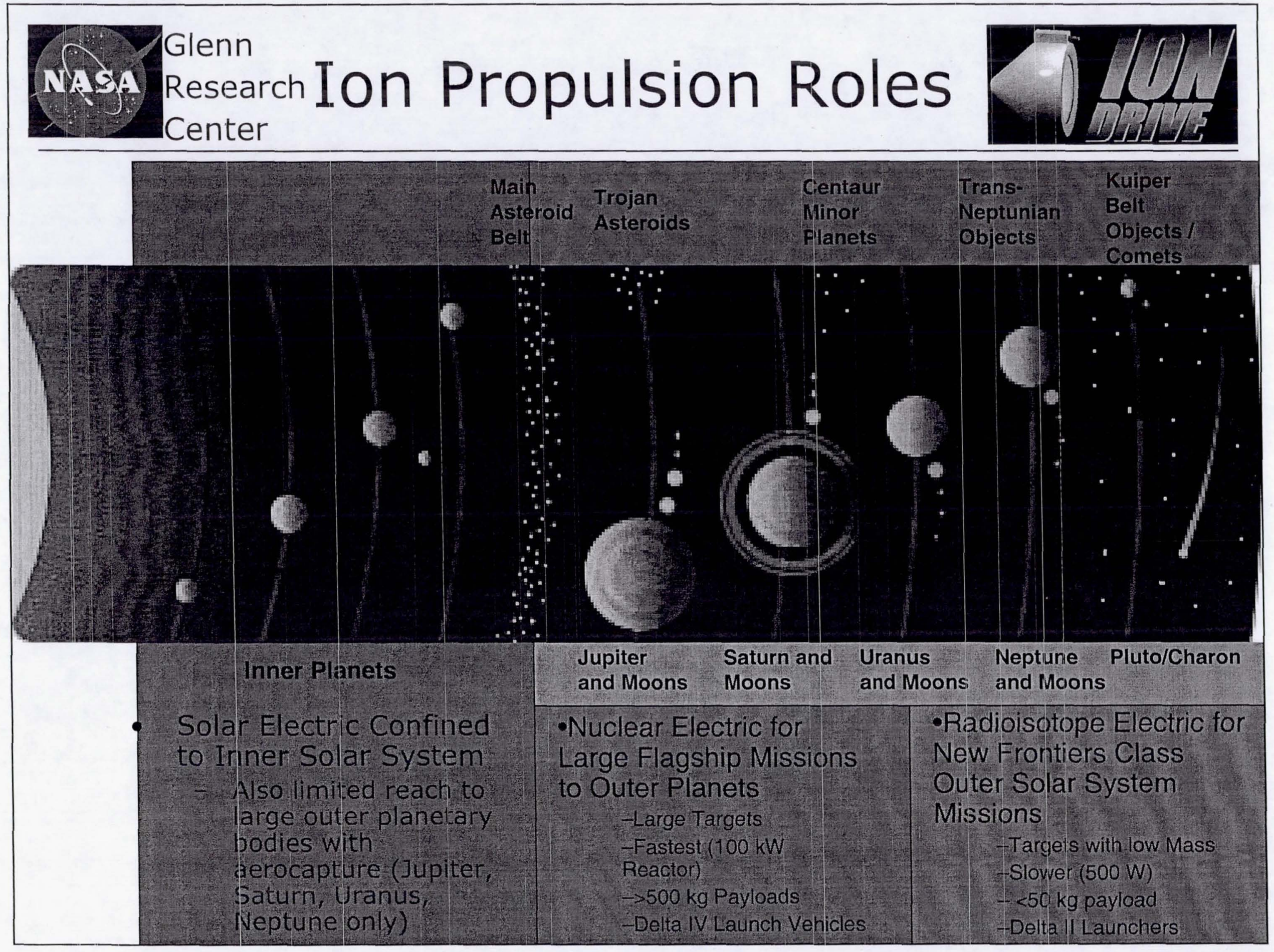




\section{Ion Engines}
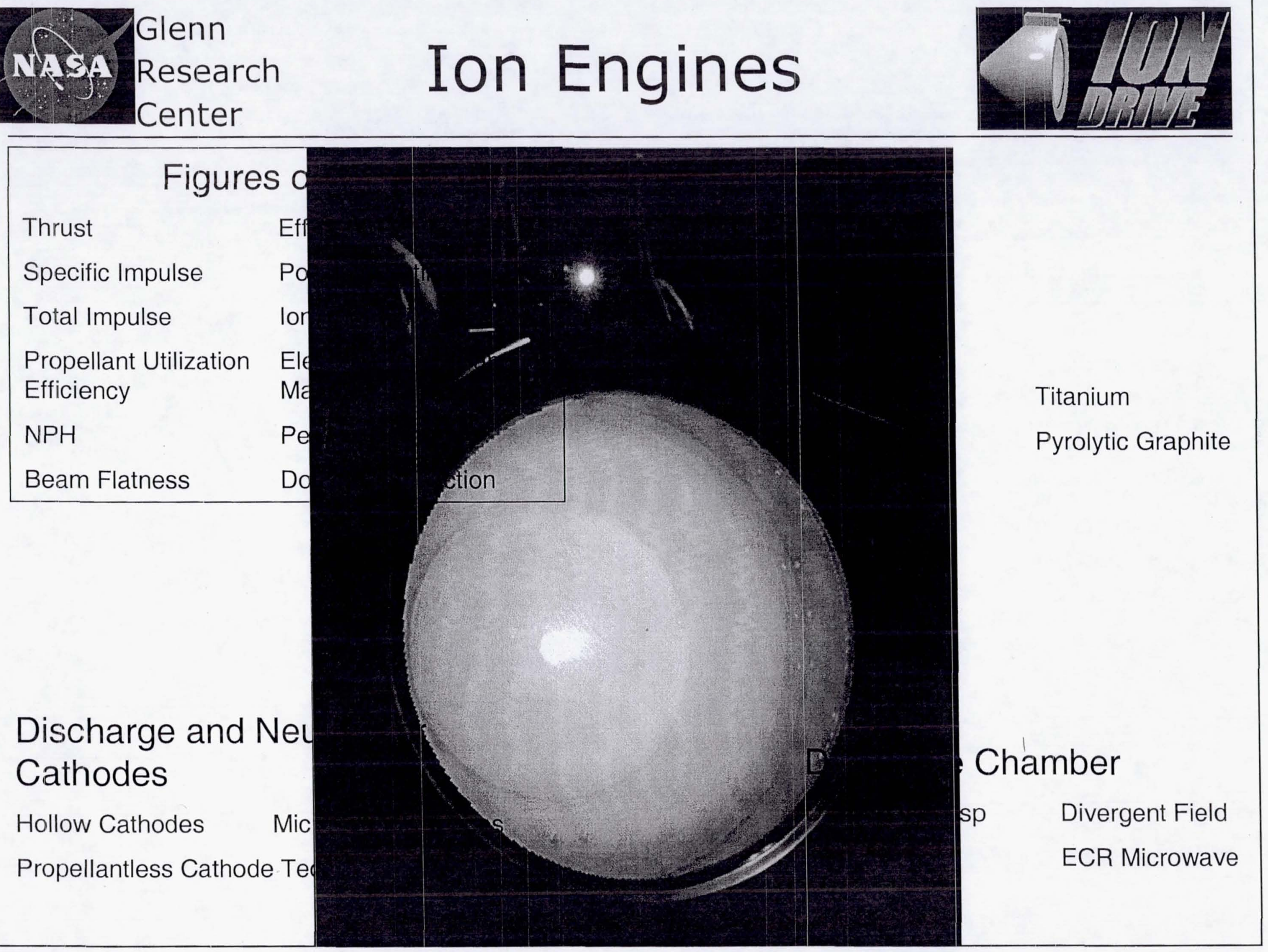


\section{NASA, $\begin{aligned} & \text { Geesearch } \\ & \text { Center }\end{aligned}$ NSTAR and NEXT}
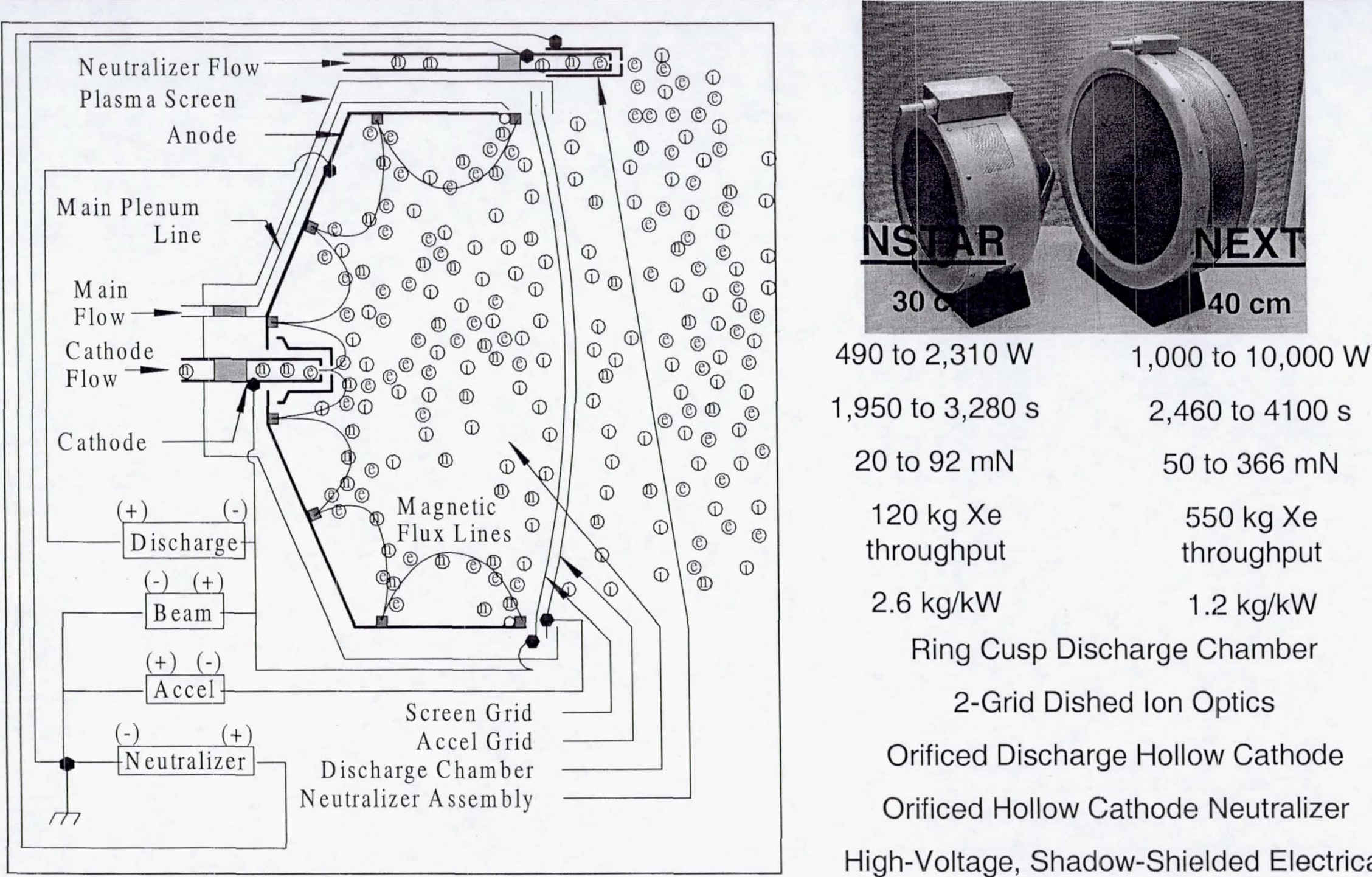

1,950 to $3,280 \mathrm{~s} \quad 2,460$ to $4100 \mathrm{~s}$

20 to $92 \mathrm{mN}$

50 to $366 \mathrm{mN}$

$120 \mathrm{~kg} \mathrm{Xe}$

throughput

$550 \mathrm{~kg} \mathrm{Xe}$

$2.6 \mathrm{~kg} / \mathrm{kW}$

throughput

Ring Cusp Discharge Chamber

2-Grid Dished Ion Optics

Orificed Discharge Hollow Cathode

Orificed Hollow Cathode Neutralizer

High-Voltage, Shadow-Shielded Electrical and Propellant Isolators

Flake Containment.Mesh 


\section{SOA NSTAR}

\section{Derated Engine Design and Operation}

- $30 \mathrm{~cm}$ design had previously been tested up to 10$\mathrm{kW}$; NSTAR limited to 2.3-kW.

- Operation at reduced perveance to improve ion optics life.

- Reduced discharge voltage prolongs component life.

\section{NSTAR / Deep Space 1 Milestones}

- First use of ion propulsion for primary spacecraft propulsion.

- Flyby of Asteroid Braille and Comet Borrelly.

- $60-\mathrm{kg}$ Xe throughput on DS1; more than 180-kg and 23,000 hours demonstrated in a wear test.

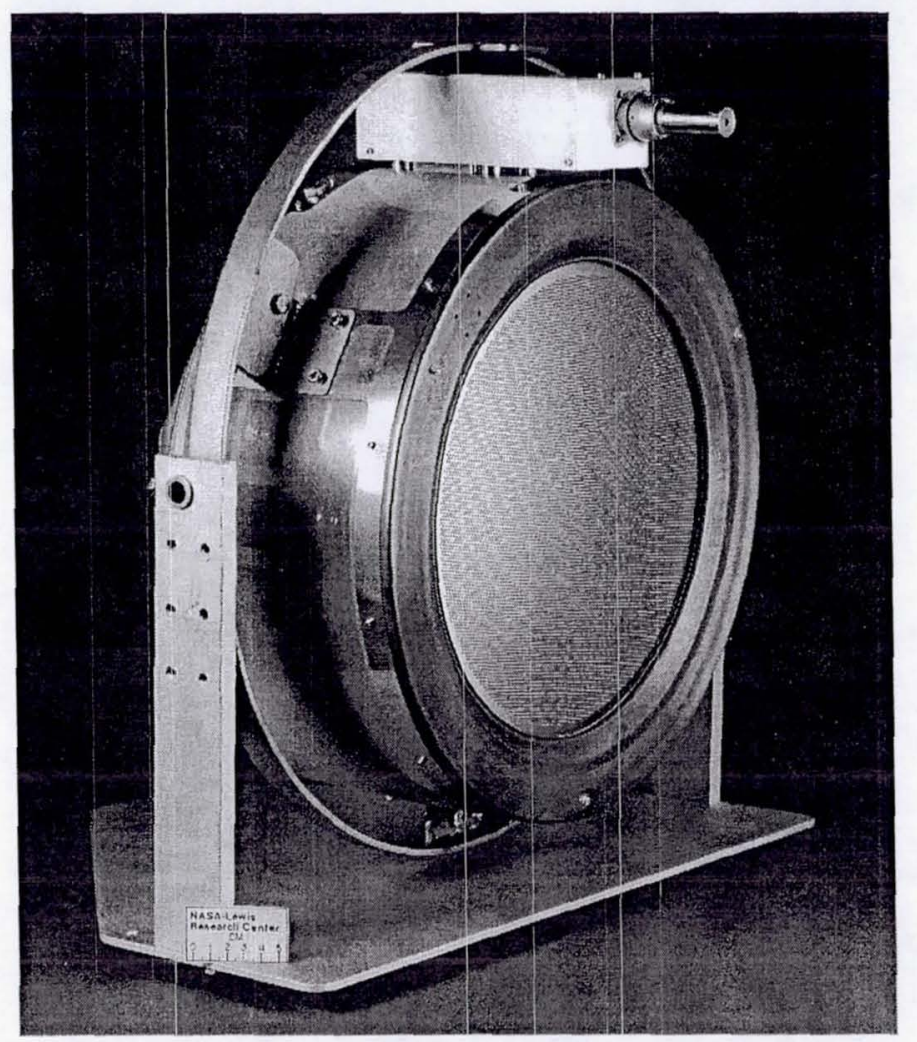

\section{Dawn Mission}

- Use three NSTAR engines in rendezvous with two asteroids. 


\section{Performance Improvements}

High $I_{\text {sp }}$ Operation

Advantages: For NEP Planetary and Deep Space; Reduces the impact of discharge losses on the overall efficiency.

Challenges: Lifetime at the elevated voltages required has not been demonstrated; very-high-voltage electrical and propellant isolators poorly developed currently.

\section{No Flow Cathodes}

Advantages: Improves true $I_{s p}$ for a given accelerating voltage.

Challenges: Space-charge limitations may require plasma cathode operation;

\section{Reduction of Discharge Losses}

Advantages: Increased efficiency; Reduces the operating temperature, prolonging the life of the magnets.

Challenges: The payoff may only be worthwhile for high-thrust-density / low I $\mathrm{sp}_{\mathrm{sp}}$ operation.

\section{Alternative Propellants}

Advantages: Reduce discharge losses with low ionization potential propellant; Reduced discharge voltage enabling substantially improved life.

Challenges: Departs from design heritage with $\mathrm{Xe}$; low ionization potential condensable propellants can coat thruster surfaces and emit electrons. 


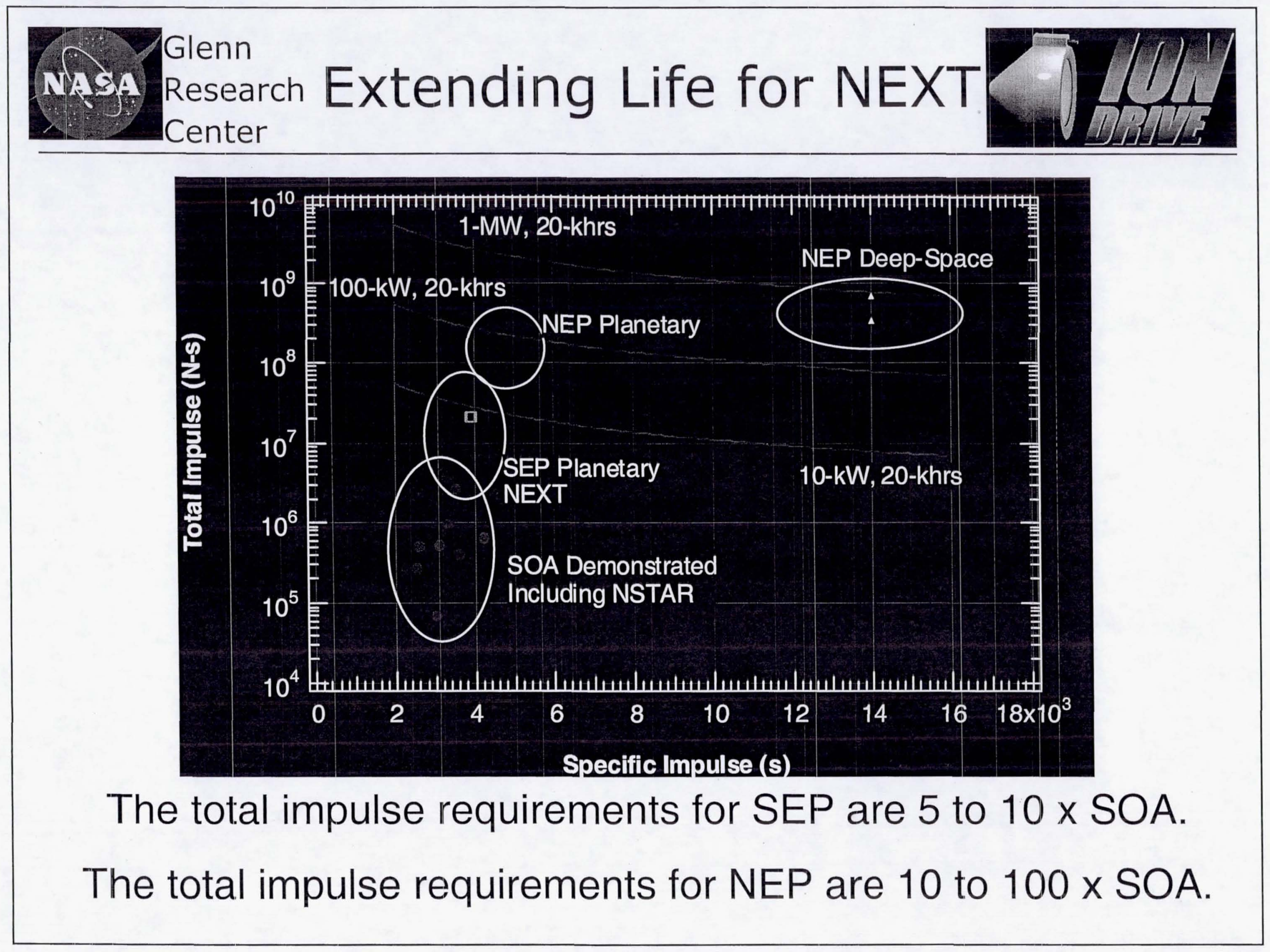




\section{Ion Optics Life}

\section{Background:}

\section{Charge Exchange lons}

-Formed from ion-neutral collisions in the Grid-Gap and downstream of the Accel Grid.

-Born at an intermediate potential, charge exchange ions accelerate toward the Accel Grid.

-Sputtering of the Accel Grid is a leading life limiting mechanism for ion thrusters.

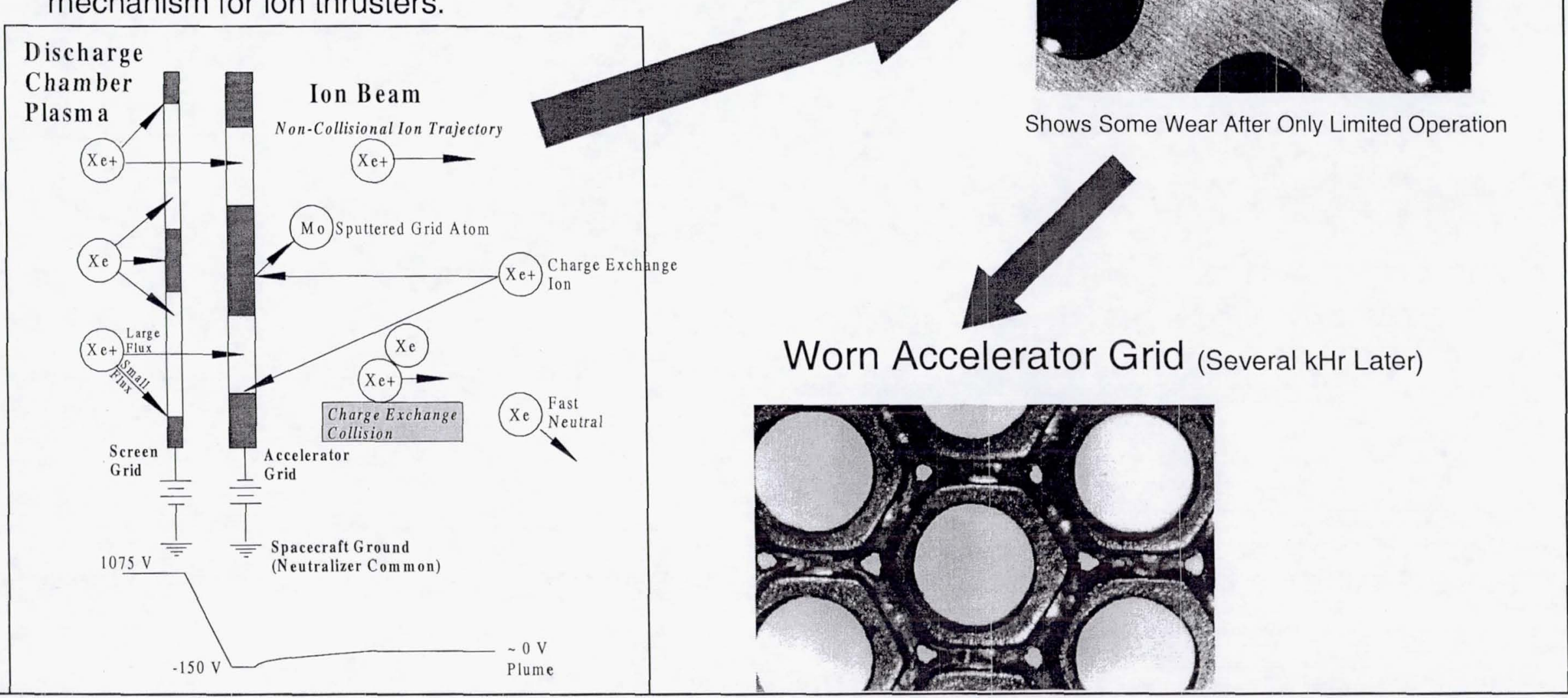




\section{Ion Optics Life 2}

\section{Beam Current Density}

- Grid EOL due to electron backstreaming

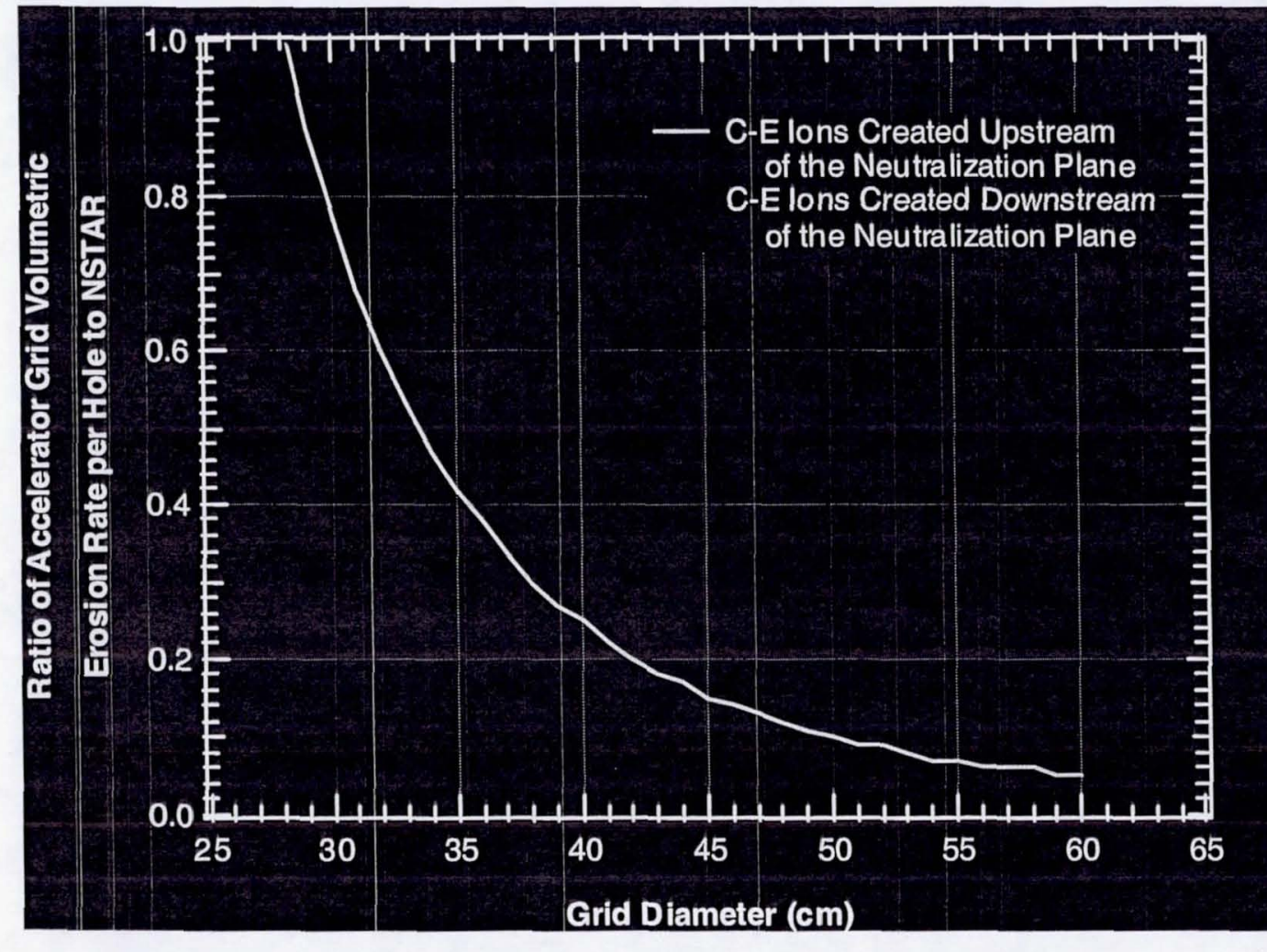
is a localized phenomenon.

Grid life based on electron backstreaming is a function of the peak beam current density.

Flat beam profiles increase thrust density capabilities while retaining the spirit of derated design.

\section{hharge Exchange Erosion}

As the chamber and grid diameter increase, the reduction in the neutral density in the discharge chamber significantly reduces local erosion rates due to ions created upstream of the neutralization plane.

G. C. Soulas, "Design and Performance of 40-cm Ion Optics," IEPC Paper No. 01-090, International Electric Propulsion Conference, Oct. 2001.

- Local erosion due to ions created downstream of neutralization plane is also reduced. 


\section{Ion Optics Life 3}

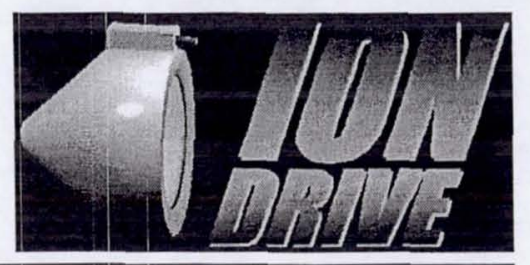

\section{Alternative Materials:}

- Titanium has low sputter yield with $\mathrm{Xe}$ at the operating voltages of interest for SEP and NEP Planetary. Implementation is complicated by start-up related thermal transients.

- Carbon-Carbon composite grids are sought for the low sputtering yield of carbon with most gases and the high strength to weight ratio. Fabrication is complicated by the desired geometry. Advanced SEP and NEP missions do not require carbon based optics.

\section{High Specific Impulse Grids:}

- Ion optics design for specific impulses from 6,000 to $15,000 \mathrm{~s}$ makes use of a large grid gap to operate at a high net-to-total voltage $[R]$ ratio. The result is that the accelerator grid potential may be kept low, and hence the charge exchange ion energy and sputter yield remain moderate. Studies at GRC and CSU have predicted lifetime to greater than 10,000 hours for high specific impulse optics independent of material.

\section{Alternative Geometries:}

- Thick accelerator grids have been fabricated and tested at GRC. The additional thickness simply provides more material to erode.

- Advance molybdenum optics have been fabricated which use a variable accelerator grid aperture size to minimize the neutral transparency of the grids. Grid alignment is more critical with this geometry than for grids with uniform aperture diameters.

\section{Screen Grid:}

- The derated operation approach employed on the NSTAR and NEXT ion engines has virtually eliminated the screen grid as a life limiter. Low voltage DC and E-M wave based discharge chambers operating at moderate beam currents are consistent with the derating approach.

- When considering operation significantly beyond the NSTAR discharge current and voltage and duration, the screen grid life must be revisited. 


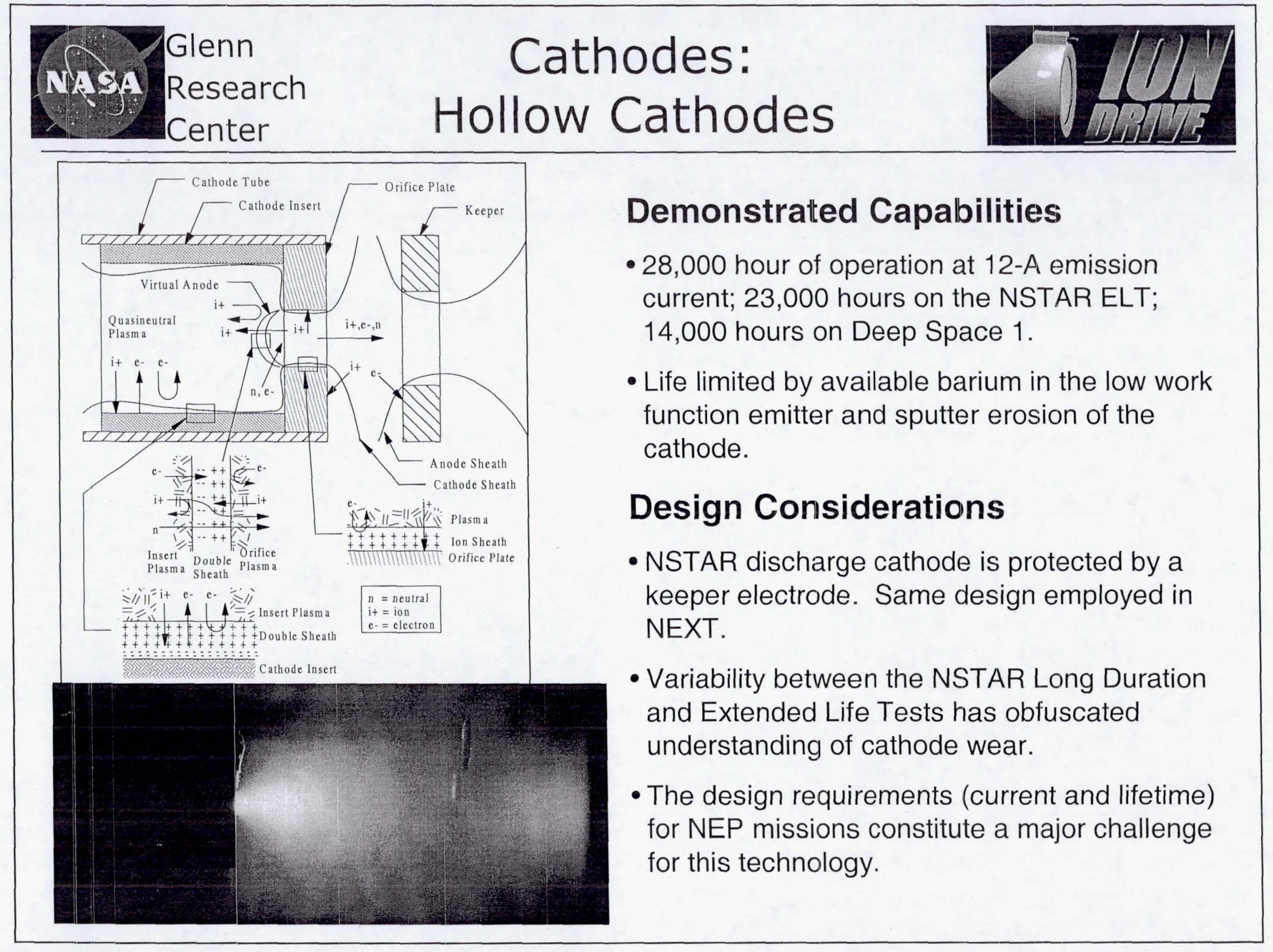




\begin{tabular}{|c|c|}
\hline Nasin $\begin{array}{l}\text { Glenn } \\
\text { Research } \\
\text { Center }\end{array}$ & $\begin{array}{l}\text { es: } \\
\text { ives }\end{array}$ \\
\hline $\int_{0}^{5}$ & $\begin{array}{l}\text { E-M Wave Base Plasma } \\
\text { Generation } \\
\text { - R-F and ECR Microwave discharge } \\
\text { chambers have been employed } \\
\text { successfully in low power ion thrusters. } \\
\text { - Microwave neutralizers have also been } \\
\text { developed. } \\
\text { - Life limited by TWT or magnetron cathode. } \\
\text { O(100 khrs) }\end{array}$ \\
\hline $\begin{array}{l}\text { Propellantlless Cathodes } \\
\text { - Ferroelectric emitters are currently } \\
\text { underdevelopment and have yielded } \\
\text { encouraging results, including the } \\
\text { possibility of stable operation in the } \\
\text { presence of a low-density plasma. } \\
\text { - Distributed electron emission may enable } \\
\text { increased beam flatness and thereby } \\
\text { extended optics life. }\end{array}$ & $\begin{array}{l}\text { Alternate Propellants } \\
\text { - Cesium can significantly improve the } \\
\text { electron emission capabilities of thermionic } \\
\text { cathodes. } \\
\text { - Use of cesium adds significant } \\
\text { complications. } \\
\text { S. K. Kovaleski, "Life-Model of Hollow Cathodes Using Barium a } \\
\text { Calcium Aluminate Impregnated Tungsten Emitter," IEPC Paper } \\
\text { No. 01-276, International Electric Propulsion Conference, Oct. } \\
\text { 2001. }\end{array}$ \\
\hline
\end{tabular}




\begin{tabular}{|c|c|}
\hline MASA $\begin{array}{l}\text { Glenn } \\
\text { Research } \\
\text { Center }\end{array}$ & $\begin{array}{l}\text { Additional Life } \\
\text { Considerations }\end{array}$ \\
\hline
\end{tabular}

\section{Low Energy Sputter Yields}

- Uncertainty in low energy sputter yields and threshold voltage severely impedes efforts to predict the life of discharge chamber components reliably.

- Additional sputter yield data down to approximately $20-\mathrm{V}$ are required to enhance life prediction ability.

\section{Flake Containment}

- The NSTAR ion engine employs a flake containment mesh which is designed to mitigate shorting events in the discharge chamber caused by sputtered material.

- NEXT is employing the same technique. Tests have shown that grit-blasted wire mesh will retain sputtered molybdenum several times in excess of the design requirement.

\section{Far Term Requirements}

- Electrical and propellant isolators have currently been flight qualified for use with $\mathrm{Xe}$ at voltages, temperatures, and for durations consistent with the NSTAR flight validation program.

- New propellant isolators are being developed for NEXT with its expanded operating envelope.
- The total impulse required for deep-space NEP missions are sufficiently far beyond the current SOA that extension of existing designs may be an inappropriate solution.

J. S. Sovey, J. A. Dever, and J. L. Power, "Retention of Sputtered Molybdenum on Ion Engine Discharge Chamber Surfaces," IEPC Paper 01-086, International Electric Propulsion Conference, Oct. 2001. 


\section{\begin{tabular}{l} 
NAsa $\begin{array}{l}\text { Glenn } \\
\text { Research } \\
\text { Center }\end{array}$ \\
\hline
\end{tabular}}

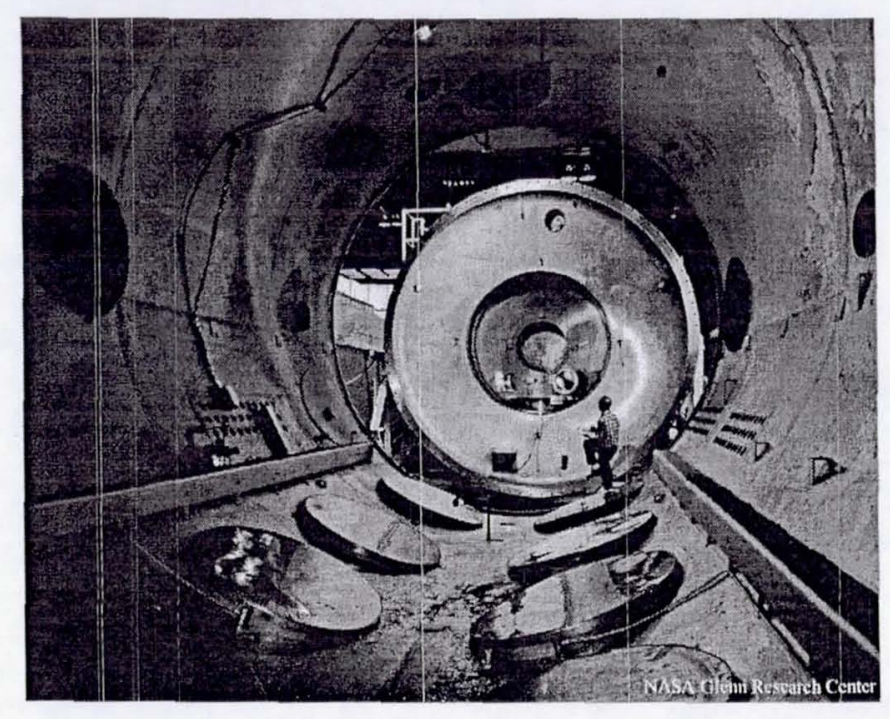

\section{Facility Sputtering}

- High $\mathrm{I}_{\mathrm{sp}}$ engines require beam dumps to ensure that the efflux of backsputtered facility material is negligible.

- Large facilities are best suited for this task.

- The number of large facilities is limited.

\section{Pumping Speed}

- For moderate $\mathrm{I}_{\mathrm{sp}}$ few facilities are suitable for operation above $50-\mathrm{kW}$.

- Condensable propellants are attractive for testing above 100-kW.

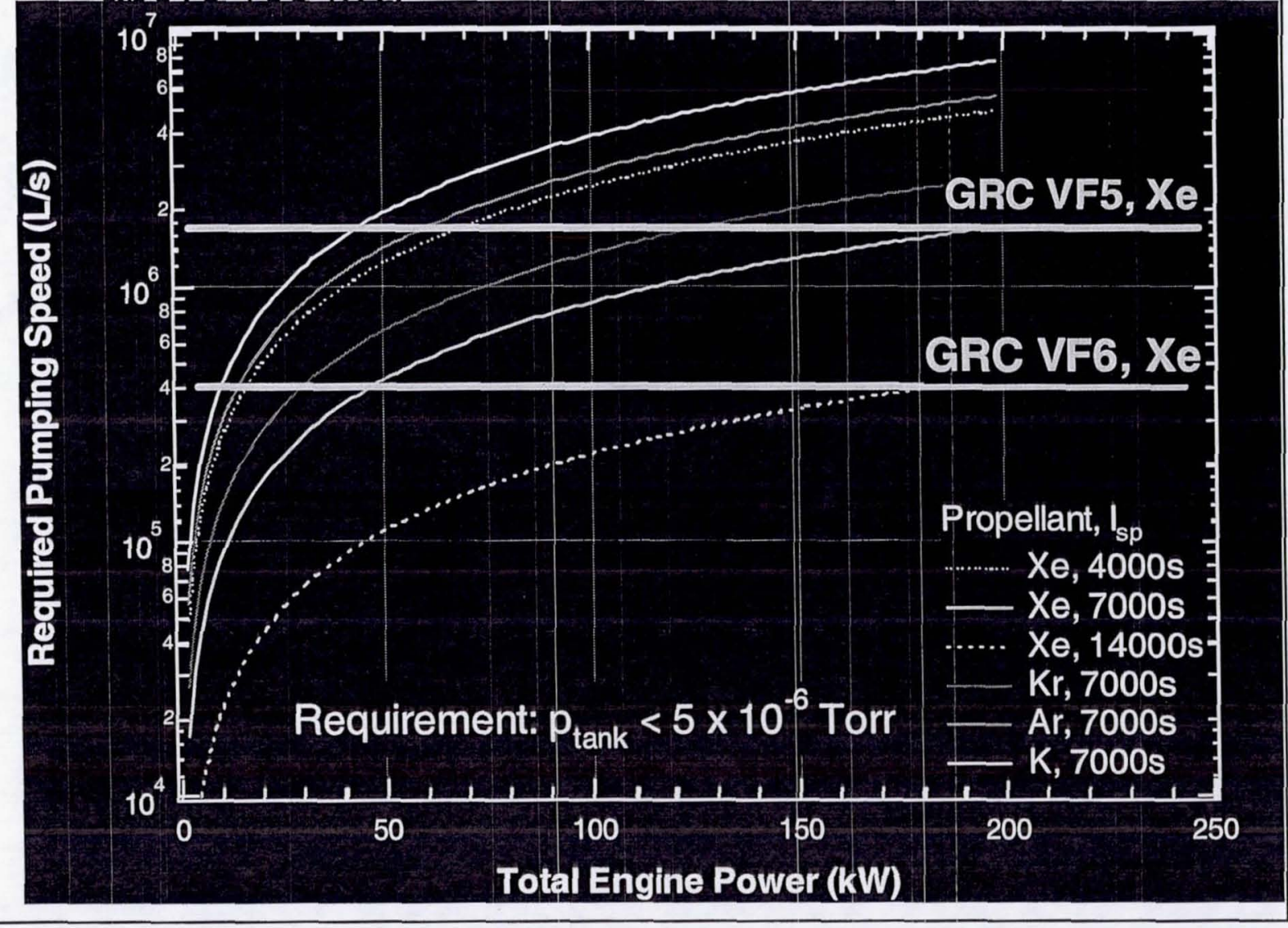




\section{Testing Considerations: Life Diagnostics}

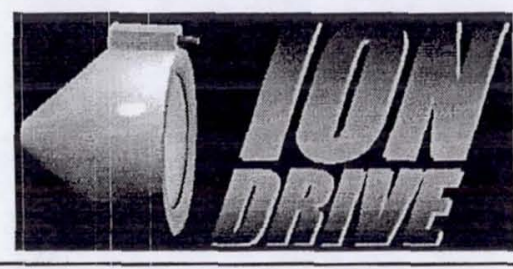

- Grid Erosion

- Measurements

- Accel Pits and Grooves

- Accel Aperture Enlargement

- Screen Grid

- Diagnostic Tools

- Laser Profilometer

- Pin gage

- CCD Imaging

- Laser Induced Fluorescence

- Discharge Cathode and Keeper Erosion

- Measurements

- Downstream Erosion

- Diagnostic Tools

- Laser Profilometer

- CCD Imaging

- ExB Probe Downstream

- LIF
- Plasma Diagnostics

- Measurements

- Beam Current Density and Divergence

- Plasma Density, Temperature, and Potential

- Beam Centroid

- Diagnostic Tools

- Faraday Probes

- Triple Langmuir Probes

- LIF

- Fidelity of Wear Test Results

- Measurements

- Backsputtered facility material

- Facility background gas composition

- Diagnostic Tools

- QCM

- Collimated Witness Plates

- RGA 


\section{Nasta $\begin{aligned} & \text { Glenn } \\ & \text { Research } \\ & \text { Center }\end{aligned}$
Life Prediction}

\section{Ion Optics}

- PIC with DSMC has been used to model the charge exchange erosion of the accelerator grid.

- Several 3-D codes have been developed.

- Limited by upstream boundary condition, neutralization plane location, and sputter yield angular distribution.

\section{Discharge Chamber}

- Magnetic field profiles are routinely predicted for ring-cusp discharge chambers.

- Detailed plasma modeling of the discharge remains elusive.

\section{Cathodes}

- Themochemical models of the insert are under development.

- First order particle models have been used to calculate discharge cathode keeper wear.

- The rapidly varying plasma density of hollow cathodes complicates modeling efforts.

\section{Increased Confidence}

- To minimize the costs associated with life-testing and validation of engines for NEP-class missions, life modeling and predictive capabilities will be increasingly relied upon. 


\section{Summary}

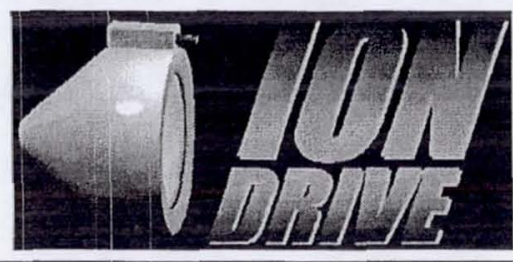

- Requirements of advanced SEP and NEP class missions will require significant advances beyond the SOA in ion engines.

- Performance at high power appears readily attainable.

- Life appears to be the major challenge for NEP class mission applications.

- Ion Optics

- Cathodes

- Discharge chambers

- Life testing and validation

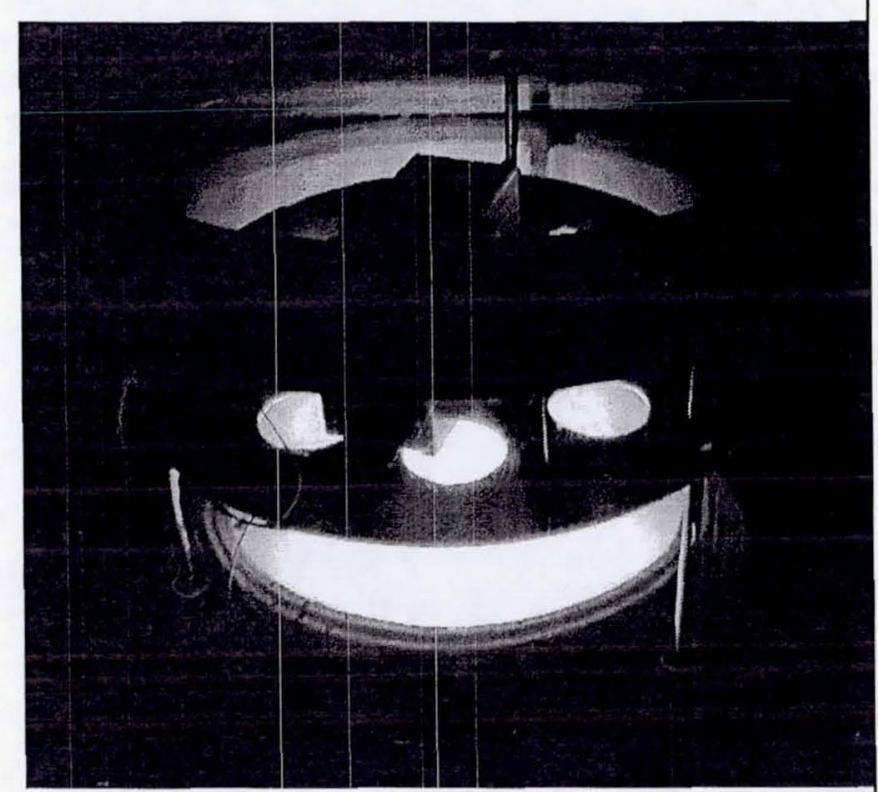

